Bol. Acad. peru. leng. 64. 2018 (127-140)

\title{
LA ANTEPOSICIÓN DEL ARTÍCULO \\ EN EL NOMBRE PROPIO: USOS PARTICULARES \\ EN EL CASTELLANO DE LIMA
}

\section{THE DEFINITE ARTICLE BEFORE PROPER NOUNS: PARTICULAR USES IN THE SPANISH OF LIMA}

\author{
Carmen Jecenia Alejandría Horna \\ Mabel Anglas Tarazona \\ Marco Antonio Lovón Cueva \\ Universidad Nacional Mayor de San Marcos
}

\section{Resumen:}

Este es un estudio exploratorio sobre la anteposición del artículo en el nombre propio en el castellano limeño. Desde el punto de vista pragmático, la anteposición del artículo en el nombre propio depende de las razones o intenciones comunicativas y la situación que hace propicio su uso. Nuestro trabajo concluye que el hablante emplea el artículo para referirse a personas de confianza o personas de las que hay burlarse.

\section{Abstract:}

This is an exploratory study on the position of the definite article before proper nouns in the Spanish of Lima. From a pragmatic point of view, the position of the definite article before proper nouns depends on communicative reasons or intentions and the situation that makes its use possible. 
This paper concludes that speakers use the definite article to refer to people they trust or to people they make fun of.

Palabras clave: artículo, nombre propio, intención del hablante, pragmática, contexto.

Key words: definite article, proper noun, speaker's intention, pragmatics, context.

Fecha de recepción: $\quad 01 / 08 / 2018$

Fecha de aceptación: $\quad 31 / 10 / 2018$

\section{Introducción}

Desde el punto de vista semántico, el nombre propio es capacitado de unicidad; esto es, se puede identificar a un individuo particular sin necesidad de usar otros complementos (NGLE 2009). No es necesario que las personas empleen el artículo antes del nombre propio, porque se entiende lo que dicen sin la necesidad de hacerlo.

Sin embargo, los usos lingüísticos revelan que se puede anteponer un artículo a un nombre propio. En estos casos, el artículo también adiciona un nuevo significado: el de familiaridad. Su aparición indica que la persona de cual se hace referencia es conocida, y además señala que existe entre el emisor y dicho sujeto cierto grado de confianza (Boluda 2012). A partir de esto, podemos decir que ciertas personas emplean el artículo antepuesto al nombre propio, porque se encuentran entre amigos o familia, porque son personas de confianza para ellos.

Los estudios sobre la anteposición del artículo son escasos. Hasta ahora no hay estudios detenidos en el ámbito sintáctico, semántico y pragmático en el castellano peruano, por ejemplo. Una manera de explicar el fenómeno es recurrir a la teoría del sintagma determinante 
https://doi.org/10.46744/bapl.201802.007

de Abney (1987), quien sostiene que en el sintagma determinante el núcleo es el determinante. Algunos hablantes hacen uso del sintagma determinante porque hay una cierta conexión entre el determinante y el nombre. Por eso, creemos conveniente realizar un estudio exploratorio sobre este fenómeno.

Nuestro trabajo trata sobre el artículo antepuesto al nombre propio de persona. Específicamente, el estudio se centra en el análisis pragmático del empleo del artículo que hacen algunas personas al referirse a otra, entre hablantes de castellano limeño. Esta variedad lingüística es hablada en el distrito de Lima por lugareños y migrantes residentes, y está asociada con la norma estándar. En esta investigación, interesa dar cuenta por qué los limeños emplean el artículo ante el nombre propio, y también en qué contexto, generalmente informales, lo usan.

Este estudio se iniciará primero con la introducción donde daremos a conocer a grandes rasgos el tema a tratar, la anteposición del artículo en el nombre propio; en el marco teórico se presentará el concepto o los conceptos en los cuales nos enfocaremos para desarrollar el artículo; en la metodología desarrollaremos, por ejemplo, el tipo de investigación que se ha realizado y las técnicas e instrumentos empleados; el análisis nos permitirá tener una explicación más precisa del tema y, por último, finalizará con las conclusiones.

\section{El nombre propio}

Los nombres propios son sustantivos que se usan para denominar a personas. El aspecto más importante de la caracterización del nombre propio es su capacidad para referirse sin la necesidad de usar otros elementos, función que no pueden cumplir los nombres comunes aisladamente.

Los nombres propios de persona se llaman antropónimos. Estos carecen de significado, pero poseen, en cambio, valor denominativo: nombran a los individuos particulares y los diferencia de otros de su misma especie. Dado que los nombres propios incorporan la noción de unicidad, se construyen prototípicamente sin artículo (NGLE, 2010). 
De acuerdo con esto, podemos comprender que el nombre propio de persona no necesita de determinantes para que se pueda entender.

Según Reyes y Marrero (2014), la significación que encierra a un nombre propio de persona es resultado único de las cualidades que los hablantes van otorgándole, que provienen, por tanto, de la propia circulación de él mismo dentro de la comunidad social donde lo emplean. Es decir, el único contexto del que se vale el nombre propio de persona para significar es el contexto social de la comunidad misma en la que se usa. Tal significado es lo que se entiende por información pragmática, puesto que a la pragmática le compete describir cómo obtenemos el sentido, es decir, la información referencial, la información intencional, el contenido implícito.

\section{El artículo}

El artículo es una clase de palabras de naturaleza gramatical que permite delimitar la denotación del grupo nominal del que forma parte, así como informar de su referencia. En efecto, el artículo especifica si lo designado por ese segmento constituye o no información consabida. Las dos clases de artículos solo aportan rasgos de definitud o indefinitud.

Los grupos nominales que llevan artículo determinado son definidos, puesto que denotan entidades que el hablante supone identificables en un contexto a partir del contenido léxico del sustantivo y de la información que comparte con su interlocutor, denominada información consabida. Alude esta información al complejo sistema de conocimientos enciclopédicos, contextuales y situacionales, así como de inferencias que se pueden deducir a partir de la información disponible. Aunque, en sentido estricto, dicha información no es siempre compartida por el receptor, el artículo determinado indica que el emisor la presenta como tal. Los grupos que llevan un artículo indeterminado son indefinidos y refieren a algo que no es conocido o no se puede modificar. En castellano son artículos definidos $e l$ y $l a$ (y sus plurales), mientras que son indefinidos un y una (y sus plurales). 
https://doi.org/10.46744/bapl.201802.007

\subsection{La estructura «artículo definido + nombre propio de persona» en el castellano}

La estructura «artículo definido + nombre propio de persona» no ha sido suficientemente estudiada desde el punto de vista histórico ni dialectal. Sobre esta última cuestión, las gramáticas suelen hacer afirmaciones generales acerca de que se trata de un fenómeno popular extendido por muchos países, pero sin mayores precisiones sobre las particularidades de uso por regiones. Tampoco, conocemos la historia de la estructura. Los dos trabajos más recientes sobre el particular (Ortiz 2009, Ciscomani y Reynoso 2012) aportan datos hasta el siglo XVI. Parece un fenómeno presente en todo el mundo hispánico, con distinta extensión social, valoración subjetiva e interpretación pragmática.

La Nueva Gramática de la Lengua Española (NGLE) se limita a decir que la presencia de artículo determinado delante del nombre de pila no convierte a los nombres propios en comunes y que este recurso es propio de la lengua popular de muchos países.

El empleo del artículo también se hace referencia para poder designar inequívocamente a un individuo que ya se conocía (Bello, 1981). También esto adiciona un nuevo significado, ya que la persona del cual se hace referencia es conocida, y además señala que existe entre el emisor y dicho sujeto cierto grado de confianza (Boluda 2012). Esto indica que las personas que utilizan el artículo antepuesto al nombre propio manifiestan una comunicación más fluida con personas que tienen cercanía y cierta familiaridad.

Martínez Leborans (1999) considera que el artículo con nombres propios no modificados (la María, el Antonio) debe interpretarse como un expletivo y que la construcción tiene carácter familiar o coloquial.

En el lenguaje formal, el artículo se usa principalmente delante de nombres comunes; nunca delante de nombres propios de personas, salvo algunas excepciones: delante del nombre de famosos poetas y artistas del Renacimiento italiano, del de famosas actrices y cantantes, 
para personas reconocidas por mucha gente también se suele usar (Velando 1917).

La anteposición del artículo también puede ser vista como un rasgo de una forma dialectal. Los hablantes de un grupo geográfico como sucede en el castellano andino o costeño en determinados grupos sociales optan por anteponer un artículo a un nombre propio, o también para expresar una mayor proximidad en el hablante a quien se dirigen colocándole el artículo. El uso que hacen ciertas personas del artículo depende del lugar donde radican o viven, ya que es una muestra de su habla cotidiana; también, este uso se realiza cuando el hablante hace mención a otra persona expresando un carácter de cercanía. Según conversación personal con el lingüista peruano Manuel Conde, se señala que el empleo que se utiliza del artículo antepuesto al nombre propio se manifiesta de una forma dialectal y se caracteriza por ser un lenguaje subestándar.

\section{Metodología}

Este es un estudio cualitativo de exploración. No se profundiza en todos los casos o usos del fenómeno en cuestión: lo que se intenta es conocer cómo es, por qué se usa y en qué contextos aparece. Es decir, buscamos acercarnos al tipo de fórmula «artículo definido + nombre propio de persona».

Para este trabajo se realizaron entrevistas, en las que se plantearon seis preguntas que nos permitieron obtener información acerca de cómo o por qué consideran que las personas tienden al uso del artículo antepuesto al nombre, en qué situaciones lo han empleado y si lo habían escuchado en un determinado lugar. La encuesta se aplicó a 40 estudiantes monolingües castellanohablantes de la Universidad Mayor de San Marcos que habían nacido o residían en Lima. Importa ante todo ser profesional porque permite observar que los usos de la anteposición no se restringen, como podría suponerse, a sectores populares o casos individuales. Las preguntas del cuestionario fueron las siguientes: 
https://doi.org/10.46744/bapl.201802.007

\section{PREGUNTAS:}

1. ¿Has empleado o escuchado usar el artículo antes del nombre propio? Ejemplo: «la María».

2. Si los has empleado, ¿en qué situación lo empleaste? Ejemplos:

3. Si lo escuchaste, ¿en dónde?

4. ¿Has escuchado el empleo del artículo en nombres de personas famosas? Ejemplo: «La Yahaira».

5. Si has escuchado, menciona algunos de ellos.

6. ¿Por qué crees que hacen uso del artículo antes del nombre propio?.

\section{Análisis}

\subsection{Las razones de la anteposición del artículo en el nombre}

En relación con los resultados de la encuesta, se determina que hay personas que no hacen uso del artículo, porque a su alrededor o en el medio en que viven no practican su uso. Algunos encuestados consideran que se trata de un uso incorrecto y descartan dicho empleo. Este grupo opina que las personas que usan el artículo antepuesto al nombre propio lo hacen por la falta de educación. Uno de los encuestados señaló: «Eso nos lleva a pensar que es un déficit de educación en nombres propios».

Sin embargo, para otros encuestados, este no es un factor para su uso. Profesionales universitarios emplean dicha fórmula; por tanto, no es porque no tengan educación, sino por la formación o interacción que han obtenido desde la infancia con el entorno que los rodea, como la familia: «Yo a mi prima le digo: "la Merci", a mi mamá, mi hermana Priscila le dice: "la Mariella", y a mi papá, "el Jorge"; a mi abuela le decían: "la Juli", por Julia». Ellos afirman que han escuchado desde pequeños el uso del artículo antepuesto en su entorno. De pequeños escucharon hablar a sus padres o a algún familiar cercano, y desde entonces asimilaron los usos de sus padres como naturales porque no fueron corregidos según la norma estándar; por eso, sienten que es normal su empleo. Una de las 
encuestadas precisó: «Porque pienso que al hablar espontáneamente las personas no se dan cuenta exactamente cómo están hablando, además porque podrían haberlo escuchado con frecuencia también emplearlo por esa misma razón». En las mismas líneas van el siguiente comentario: «Lo usan en una conversación espontanea por el grado de confianza, no establecen lo que van a decir solamente fluye la conversación» y «Porque están acostumbrados a anteceder un determinante a cualquier cosa u objeto, en general, que sea nombre; básicamente por costumbre». Por su lado, otros encuestados señalaron lo siguiente: «Por el entorno que te rodea como la familia, amigos. El uso habitual dentro de la sociedad es también una razón» $\mathrm{y}$ «Por lo que escucharon desde niños o niñas de sus padres o personas con las que viven. También porque escucharon de los amigos». Un encuestado también indica lo mismo: «Pues he notado que muchos lo hacen en conversaciones de tipo familiares. Cuando quieren hacer que la expresión sea más afectuosa, por así decirlo».

Argumentan también que usan el artículo para indicar el género de la persona; esto es, lo emplean cuando existen un nombre que puede ser usado tanto para hombre como para una mujer y para poder definir a qué persona se le está nombrando. En este caso, el artículo se utiliza para marcar una diferencia respecto a qué género se estaría refiriendo para evitar una posible equivocación. Uno de los encuestados señaló: «Porque mi competencia lingüística me dice que lo haga, en caso contrario, encuentro que existe cacofonía».

Incluso, algunos encuestados señalan haber escuchado en términos despectivos nombrar a una persona con la anteposición del artículo, sobre todo cuando se refieren a empleadas del hogar, trabajadores del hogar, como un jardinero, o también a vendedores del mercado. Algunos usos son «La María», «La Juanita», «El Pancracio». Muchas veces también sucede que esos no son sus nombres reales, pero quienes los denominan así les asignan el artículo y el nombre. Ellos pueden llamarse Rosa, Britanny o Rodrigo, pero les aplican la estructura «artículo definido + nombre propio de persona». En este caso, tanto el artículo como el nombre presentan una carga valorativa poderosa. Hay nombres que se estereotipan con ciertas labores o juicios. 
https://doi.org/10.46744/bapl.201802.007

Queremos advertir que otra forma de burlarse de los interlocutores es colocar un artículo femenino a un nombre de hombre. En nuestros datos, algunos encuestados señalaron que recurren a esta estrategia para fastidiar a su compañero o hablar mal de alguna persona. Ejemplo de ello son los casos «La Piero», «La Roberto» o «La Robert». Una forma de feminizar a los individuos varones en castellano limeño, y diríamos peruano, es mediante la anteposición de un artículo con un género diferente al género del nombre. En otro sentido, esta estrategia pragmática es muy usual entre varones, quienes se mofan entre sí. También es muy común este uso en la comunidad gay. Los homosexuales en contextos de amicalidad tratan a sus compañeros empleando dicha estrategia. Ejemplo de ello es cuando nombran a un amigo llamado «Carlos» con la variante «la Carlota». En relación con todo esto, debemos advertir que no es usual el empleo en el caso contrario: no aparecen ejemplos en el que se use un artículo de género masculino para un nombre femenino. La explicación puede deberse a que la cultura machista imperante busca desprestigiar a los hombres poco varoniles o hacerlos ver como tales frente a otros que construyen su imagen más varonil o de machos.

Los encuestados también señalaron que usan el artículo antepuesto al nombre con un sentido de menosprecio o burla, para desprestigiar muchas veces el aspecto físico, la forma de vestir o ciertos rasgos que presente la persona referida. Un ejemplo de ello es el caso de «el Brayan». Aquí, se usa para referir a un hombre que se asocia a rasgos de un delincuente, también a una persona que no viste bien o que presenta un mal aspecto físico y un corte de cabello peculiar. Es decir, se le denomina «el Brayan» a un hombre que se percibe de forma negativa en el Perú. Sus equivalentes son «el Brandon» y «el Kevin». En el caso de las mujeres, es «la Brittany». Una de las encuestadas nos señaló que este tipo de usos llega hasta ser una categoría adjetival: «Él es medio Bryan». Aquí la fórmula es otra: el nombre propio pasó a ser adjetivo, con significado de ‘tonto' o 'ridículo'.

Hemos observado en las respuestas de los alumnos encuestados que algunos de ellos han escuchado el empleo del artículo para referirse a personas famosas, ya sea en periódicos, en programas de televisión, en 
noticias de la farándula o en anécdotas. Algunos de los ejemplos que nos han brindado los alumnos encuestados sobre este empleo es «la Thalia», «la Sheyla», «la Gisela», «la Yahaira», «la Tula». Aunque se tratan de personas famosas, también hay una carga social que traen estas denominaciones asociadas para los encuestados con cultura popular, barrio o barriada, o el morbo, como sucede con «el Guty». Incluso, hay expresiones como «Eres la Yahaira del barrio», sin llamarse realmente Yahaira o, en forma corta, también, aparece la forma: «Eres la Yaha». Al respecto, algunos encuestados piensan que el uso responde a la moda.

En la encuesta, se ha observado que en una de las preguntas realizadas a los alumnos en los programas de televisión o de espectáculos, utilizan este tipo de vocabulario cuando hacen referencia a una persona famosa.

Como sabemos, en el lenguaje formal, el artículo se usa principalmente delante de nombres comunes; nunca delante de nombres propios de personas, salvo algunas excepciones: delante del nombre de famosos poetas y artistas del Renacimiento italiano, de famosas actrices y cantantes, para personas reconocidas por mucha gente también se suele usar (RAE 1917). Podemos percibir que este tipo de lenguaje se usaba para nombrar a personas famosas, pero básicamente mujeres, como las poetas y escritores.

\subsection{Las situaciones de uso}

Respecto de las situaciones, los encuestados describen que la mayoría de los escenarios de uso son los contextos de familiaridad.

De acuerdo con la encuesta que hemos podido recolectar, los encuestados nos manifiestan que este uso generalmente se emplea en distintas situaciones, en ciertos grupos de personas que presentan una cercanía, como familiares, amigos, en un ambiente primordialmente de confianza y relación de parentesco. Este lenguaje coloquial tiende a utilizarse cuando existe una relación de proximidad. 
https://doi.org/10.46744/bapl.201802.007

De acuerdo con las repuestas de los encuestados, podemos apreciar que algunos de ellos nos dicen que utilizan el artículo antepuesto al nombre propio sin darse cuenta o de forma inconsciente, ya que están hablando espontáneamente por el grado de confianza. Por ello, al no tener la conciencia de la forma expresada, sobre el uso del artículo, la conversación solamente fluye.

En relación con ello, hubo encuestados que nos manifiestan que lo utilizan porque ya están acostumbradas a usar un determinante ante cualquier cosa u objeto, por lo que les resulta «normal» decirlo de dicha manera.

Además, los alumnos encuestados opinan que al escuchar en repetidas ocasiones dicho fenómeno hacen uso del artículo ya sea en el barrio que viven, con amigos o familiares; por esta razón, es que ellos asimilan esta forma de expresar.

También lo utilizan cuando pretenden satirizar a alguien. Ello depende mucho de la situación en la que se encuentran para burlarse de sus interlocutores.

\section{Conclusiones}

El uso del artículo ante el nombre propio por castellanohablantes de Lima es empleado generalmente con personas que comparten un mismo entorno, sea familiar, amical, laboral, escuela, universidad. Basándose en la relación cercana que poseen con ciertas personas, han adquirido un nivel de confianza que les permite tener una comunicación más fluida en la que se intercambian fórmulas lingüísticas que la norma estándar no acepta. Como se vio, hay diferentes opiniones en los usos que se dan al artículo, uno de ellos es que lo usan por costumbre, otros por la confianza que se comparte con ciertas personas, también por su entorno familiar a base de haber asimilado esa forma de habla; otros usos son los peyorativos, es decir, los usos que no se dan con respeto, sino que lo realizan de manera que transmite una connotación negativa o de desprecio. En términos pragmáticos, en contextos peyorativos, este estudio muestra que la 
anteposición del artículo sirve como una estrategia para infravalorar a personas que no son bien apreciadas o que se las estigmatiza como diferente o poco capaz.

Sobre la base de a la encuesta realizada, se ha obtenido que el uso del artículo lo emplean los hablantes que viven en la selva peruana o proceden de esa zona. Es decir, no es un uso privativo de los hablantes en Lima, por lo que sería interesante realizar investigaciones más profundas. Se suele afirmar que la estructura «artículo más nombre propio» pertenece a la lengua popular de algunos dialectos; en otras palabras, es una estructura estigmatizada (Reynoso 2008). La estructura no es privativa del castellano limeño.

Finalmente, advirtamos que la anteposición del artículo no solo aparece con nombres de pila, sino también con apellidos: «La Soifer», «el Farfán», «el Martel». De forma pluriverbal, puede aparecer, aunque de forma escasa, por los datos recabados, la anteposición del artículo con el nombre de pila y el apellido en casos como «el Marco Lovón, «el Marco Tocas», «el Marco Martos», «la Carolina Arrunátegui», «la Mercedes Palomino», «la Magaly Arcela». En estos casos, aparentemente, se quiere marcar con precisión de quién se está hablando; se evita generar a toda costa posibles casos de ambigüedad.

Asimismo, en términos de sintaxis y lexicalización, vemos que la anteposición del artículo aparece frente a cualquier nombre, como sucede con «la Carolina» o «el Marco»; sin embargo, hemos encontrado casos en los que el artículo está tan fundido a un único nombre, que termina por lexicalizase, como vimos en los casos de «el Bryan». 
https://doi.org/10.46744/bapl.201802.007

\section{BIBLIOGRAFÍA}

ABNEY, S. (1987). Sintagma determinante y del sintagma nominal, Tesis doctoral, MIT.

BOLUDA, M. (2012). Oralidad y escritura en documentos notariales del siglo XVIII en el marquesado de los Vélez (Tesis doctoral). Murcia: U de Murcia.

BOSQUE, I., DEMONTE, V., LÁZARO, C. PAVON, L. (1999). Gramática descriptiva de la lengua española: Vol. 1. Madrid: Espasa Calpe.

CISCOMANI, R. y REYNOSO, J. (2012). La determinación y el nombre propio: Un estudio histórico de pragmática social en español. Actas del VIII congreso internacional de historia de la lengua española. Ed. Emilio Montero Cartelle. Santiago de Compostela: Meubook.

FERNÁNDEZ, M. (1999). El nombre propio. Gramática descriptiva de la lengua española. Ed. Ignacio Bosque y Violeta Demonte. Madrid: Espasa-Calpe.

GARCÍA, C. (1985). El artículo ante nombre propio de persona (Tesis doctoral). Lapesa. Madrid: Universidad Complutense.

GARRIDO, J. (1988). Sobre la evolución hasta el artículo actual en español. Actas del I congreso internacional de bistoria de la lengua española. Ed. Manuel Ariza Viguera, Antonio Salvador Plans, y Antonio Viudas Camarasa. Madrid: Arco.

KING, J. (2011). Structuring Conversation: Discourse Markers in Cervantes Entremeses. Hispania.

LAPESA, R. (2000). Del demostrativo al artículo. En Estudios de morfosintaxis histórica del español. Madrid: Gredos, 2000.

Bol. Acad. peru. leng. 64(64), 2018 / e-ISSN: 2708-2644 
LEONETTI, M. (1999). El artículo. Gramática descriptiva de la lengua española. Ed. Ignacio Bosque y Violeta Demonte. Madrid: Espasa-Calpe.

ORTIZ, R. (2009). La creación y generalización del artículo definido. Sintaxis histórica de la lengua española. Segunda parte: La frase nominal. Ed. Concepción Company. México: Fondo de Cultura Económica.

REAL ACADEMIA ESPAÑOLA y ASOCIACIÓN DE ACADEMIAS DE LA LENGUA ESPAÑOLA. (2009). Nueva gramática de la lengua española (NGLE). Madrid: Espasa.

REYES, J. y MARRERO, V. (2014). Información pragmática del antropónimo más allá de su valor referencial. Anuario de Lingüística Hispánica, 30, 145-164.

VELANDO, M. (1917). Los criterios de corrección en las gramáticas de la Real Academia Española. Boletín de la Real Academia Española. 